\title{
The World Congress for Ultrasound
}

The line-up of speakers for the WFUMB 2019 Congress is outstanding; over 120 ultrasound experts will deliver the exceptional program. Plus, take the opportunity to explore Australia!

\section{Most Influential Radiology Researcher 2018 Semi-finalist - Welcome Dr Richard Barr}

Dr Richard Barr is a Professor of Radiology at Northeast Ohio Medical University and has been involved in elastography and ultrasound contrast for over 15 years; presenting over 400 scientific and educational presentations and invited lectures worldwide.

The current Editor-in-Chief of Journal of UItrasound in Medicine, Dr Barr has published over 100 peer reviewed papers, several book chapters, and books "Breast Elastography" and "Elastography, a Practical Approach".

Aunt Minnie named him a semi-finalist for the Most Influential Radiology Researcher in 2018.

Dr Barr will be presenting on day 2 of the Congress:

- Breast - How to incorporate strain and shear wave Elastography into your practice?
- General liver - WFUMB guidelines liver elastography

- General abdomen - Re-defining Bozniak with CEUS of complex renal cysts

Click here to see the Congress speakers, click here to see the Congress program. Don't miss out, REGISTER NOW.

We sincerely hope you take this opportunity to be a part of the world congress for ultrasound and we hope you take the chance to extend your stay and enjoy some of the amazing sights of Melbourne and the rest of Australia.

Melbourne is an exciting, ever-changing city with extraordinary surprises to be discovered in every laneway, rooftop and basement. A city that regularly tops the World's Most Liveable list, there's always something going on with an enviable array of major events and festivals.

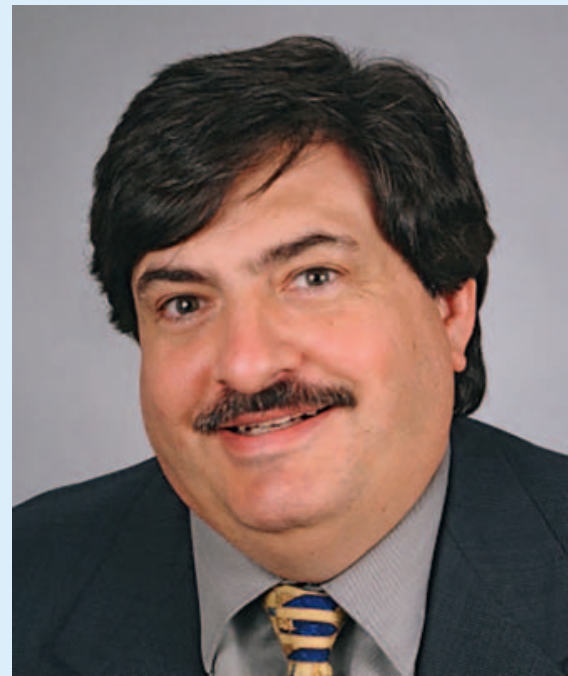

Known for its style and sophistication, Melbourne exudes a distinct bohemian charm with its maze of hidden laneways, opulent bars, exclusive restaurants, charming gardens and off-the-beaten-track boutiques. It's also a cultural hub of museums, galleries and music venues.

\section{Internationally recognised MSK radiologist - Welcome Dr Ronald Adler}

With 30 years of experience performing MSK ultrasound, WFUMB is proud to host Dr Ronald Adler, a Professor of Radiology at the NYU Langone Medical Center, New York.

Dr Adler's primary research interests have included ultrasound guided interventions and applications of blood flow imaging, assessment of soft tissue mechanical properties to evaluate bone-tendon healing and skeletal muscle. He authored or co-authored 200 papers and 26 book chapters.
Dr Adler has previously developed MSK ultrasound programs at the University of Michigan and the Hospital for Special Surgery in New York.

Dr Adler will be presenting Using ultrasound contrast agents to assess tendon healing on day 1 of the Congress and MR-US Fusion Techniques for MSK Interventions on day 2.

Click here to see the Congress speakers, click here to see the Congress program. Don't miss out, REGISTER NOW.

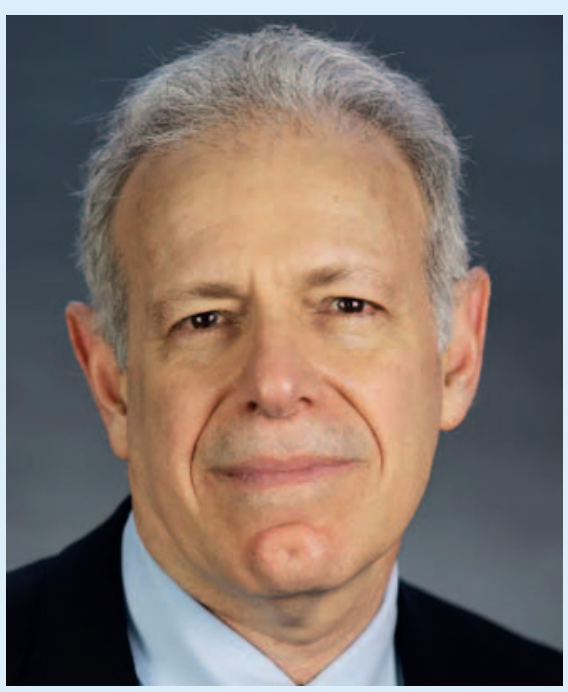




\section{Platinum Sponsor - GE Healthcare}

Thank you to WFUMB 2019 Congress Platinum Sponsor, GE Healthcare.

The support of sponsors like GE Healthcare, is essential to ensure the ongoing success of events that support and develop the local and international ultrasound industry.
Visit GE at WFUMB 2019 to see first-hand how the LOGIQ E10's new approach to acquiring and reconstructing data in a similar way to MRI or CT systems, delivers image uniformity from near to far field. The result? Focal zones become a thing of the past as every pixel is in focus producing in- credibly detailed images faster than ever before. High quality, efficient exams across a wide variety of clinical applications - even technically challenging cases such as high BMI or advanced disease. Learn more

\section{Gynaecology Keynote Speaker - Welcome Dr Wouter Froyman}

Dr Wouter Froyman is a doctoral researcher in the International Ovarian Tumor Analysis (IOTA) group. The subject of his current thesis is the development and validation of diagnostic methods (i.e. in imaging, ultrasound in particular) for the management of patients with adnexal masses, with a focus on the investigation of the long-term behaviour of adnexal lesions followed conservatively (IOTA phase 5). He is also coordinating the ongoing studies IOTA phase 7 and IOTA-MRI.

An invited speaker at over 25 national and international conferences and trainings, $\mathrm{Dr}$ Froyman received the Dame Hilda Lloyd Congress Medal for best abstract at RCOG 2016 in Birmingham, and in 2017, he received the best abstract award at the ISUOG World Congress.

\section{Stay up-to-date}

For registration, program, sponsorship, venue information and more, visit the website - www.wfumb2019.org
Dr Froyman will be presenting in the gynaecology sessions Managing ovarian masses: how to classify them using IOTA terminology and From ovaries to endometrium: how do we differentiate benign from malignant? on days 1 and 2 of the Congress:

- What are IOTA easy descriptors and simple rules: How to use them

- Balancing risks of surgery with risks of conservative management of benign adnexal masses

- Solid ovarian masses: Lessons and pitfalls

- Reporting the endometrium and intracavitary lesions using IETA terminology

Click here to see the Congress speakers, click here to see the Congress program. Don't miss out, REGISTER NOW.

Follow us on Facebook and Twitter to ensure you don't miss any updates.

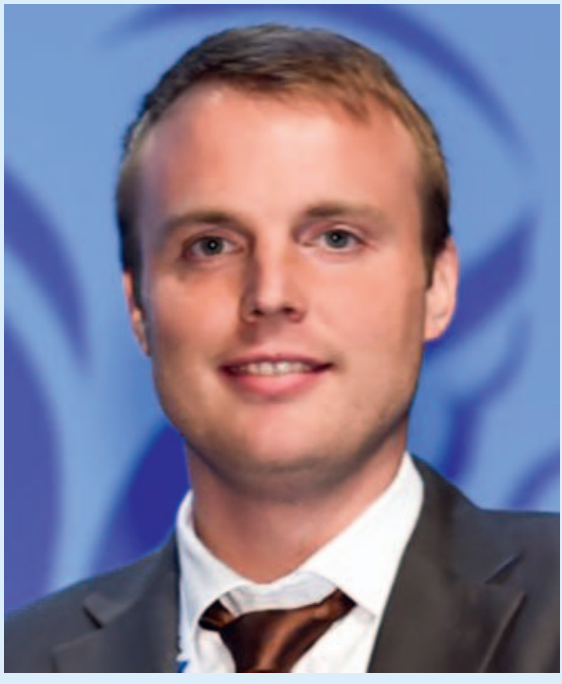

Be part of the conversation, use \#WFUMB19 \#ASUM19. 